\title{
ARGÜIÇÃO DE DESCUMPRIMENTO DE PRECEITO FUNDAMENTAL: UM MECANISMO DE CONTROLE DAS NORMAS CONSTITUCIONAIS ORIGINÁRIAS
}

Carlos Eduardo de Freitas Fazoli* Carlos Alberto dos Rios Junior**

\section{Resumo:}

Ainda não há consenso na doutrina acerca do objeto e finalidade da Argüição de Descumprimento de Preceito Fundamental. É certo que o instituto deve ser interpretado à luz da Constituição e não da lei ordinária. Neste sentido, pode ser um importante instrumento na defesa de preceitos fundamentais em face das próprias normas constitucionais originárias.

Palavras-chave: Direito Constitucional, Argüição de Descumprimento de Preceito Fundamental, Normas Constitucionais Originárias, Controle.

\section{Introdução}

A Argüição de Descumprimento de Preceito Fundamental, importante instrumento de proteção dos direitos básicos, ainda é um tema pouco explorado no direito brasileiro. Com efeito, segundo as estatísticas do Supremo Tribunal Federal $^{1}$, ao passo que já foram propostas mais de quatro mil Ações Diretas de Inconstitucionalidade, foram ajuizadas pouco menos de cento e setenta Argüições de Descumprimento de Preceito Fundamental. Deste número, noventa e nove foram julgadas até a data da elaboração deste artigo, sendo que apenas três tiveram resolução de mérito e o primeiro deles foi no ano de 2005.

Os dados demonstram que o Supremo Tribunal Federal ainda está construindo sua jurisprudência sobre o tema. Na doutrina nacional, ainda são poucos os autores

\footnotetext{
* Mestre em Sistema Constitucional de Garantia de Direitos - ITE/Bauru. Especialista em Direito Civil e Direito Processual Civil - INPG/UNIARA/Araraquara. Professor dos cursos de graduação e pós-graduação lato sensu em Direito do Centro Universitário de Araraquara - UNIARA/Araraquara. Professor convidado do curso de pós-graduação lato sensu em Direito da UNITOLEDO/Araçatuba. Procurador da Fazenda Nacional.

** Mestrando em Sistema Constitucional de Garantia de Direitos - ITE/Bauru. Procurador da Fazenda Nacional.
}

'Disponível em: http://www.stf.jus.br/portal/cms/verTexto.asp?servico=estatistica\&pagina=adpf $>$. 
que tratam do assunto com a profundidade devida, sendo que existem pontos obscuros que sequer foram debatidos.

Percebemos, analisando a doutrina e a jurisprudência, que houve uma maior preocupação dos operadores do direito em estudar a Argüição de Descumprimento de Preceito Fundamental a partir da promulgação da lei infraconstitucional regulamentadora. Infelizmente, poucos são os estudos que realizam uma interpretação da Argüição de Descumprimento de Preceito Fundamental à luz da própria Constituição².

Neste artigo, discorreremos sobre o instituto apontando alguns mecanismos semelhantes existentes no direito comparado, a argüição de descumprimento de preceito fundamental na constituinte, a lei reguladora e finalmente, uma importante função no sistema constitucional brasileiro atingida através de uma nova leitura do dispositivo constitucional.

\section{Direito comparado}

No direito comparado, existem alguns mecanismos que guardam certa semelhança com a Argüição de Descumprimento de Preceito Fundamental contida no Texto Constitucional de 1988. Trataremos de algumas delas, indicadas por André Ramos Tavares (2001).

No direito norte-americano, encontramos o writ of certiorari, que é uma espécie de mandado de avocação, onde o interessado, no bojo de seu processo judicial particular, pode provocar uma espécie de "incidente" de inconstitucionalidade, ao visualizar lesão a direitos fundamentais, e, assim, tentar o deslocamento do feito para a Suprema Corte Americana. Não há a necessidade do esgotamento prévio das instâncias ordinárias. Porém, a Suprema Corte decidirá discricionariamente se avocará ou não o processo.

No direito alemão, há o agravo constitucional ou recurso constitucional, também funcionando como um incidente nos processos particulares, com iniciativa das respectivas partes. A regra, no sistema tedesco, exige o exaurimento das instâncias ordinárias. Porém, o Tribunal Constitucional admite exceções quando houver, na causa, "interesse nacional".

Muito semelhante ao sistema alemão, no direito espanhol existe o recurso de amparo, como um incidente nos processos onde houver lesão a direito fundamental.

No direito bávaro existe a Popularklage, que é uma verdadeira ação direta de

${ }^{2}$ Talvez isso ocorra por conta da força que o positivismo jurídico (ainda) tem em nosso país. Por aqui, a norma infraconstitucional parece direcionar a Constituição, numa completa e injustificada inversão de valores.

REVISTA UNIARA, $n .^{0} 21 / 22,2008 / 2009$ inconstitucionalidade de iniciativa popular, onde o interessado pode confrontar a validade de leis e regulamentos que lesionem direitos fundamentais.

Os exemplos acima, embora possuam pontos de contato com a Argüição de Descumprimento de Preceito Fundamental, não guardam com esta correspondência absoluta, o que torna o instituto único e puramente brasileiro.

\section{A argüição de descumprimento de preceito fundamental na constituinte}

No primeiro texto do projeto da atual Constituição (o chamado "Projeto A") não havia a previsão da Argüição de Descumprimento de Preceito Fundamental (TAVARES, 2001). Esta, então, foi incluída através de uma emenda. Muito embora tenha recebido parecer desfavorável do Relator Geral da Constituinte, a emenda foi aprovada e entrou em vigor com a Constituição de 1988.

Cinco anos depois, experimentamos a Revisão Constitucional e, com ela, a proposta do deputado Adroaldo Streck de supressão do dispositivo da Argüição de Descumprimento de Preceito Fundamental do texto constitucional, pois, segundo o parlamentar, lhe faltava utilidade ${ }^{3}$. Felizmente, este instituto sobreviveu à revisão e permanece em vigor.

\section{Topografia do instituto e classificação da norma}

Na seção da Constituição que definiu a competência do Supremo Tribunal Federal, está insculpida a norma referente à Argüição de Descumprimento de Preceito Fundamental, no artigo. 102, parágrafo primeiro, in verbis: "A argüição de descumprimento de preceito fundamental decorrente desta Constituição será apreciada pelo Supremo Tribunal Federal, na forma da lei".

Nossa Corte Constitucional entendeu ser uma norma de eficácia limitada ${ }^{4} \mathrm{em}$ razão da expressão "na forma da lei". Vale dizer, então, que para o Supremo Tribunal Federal a Argüição de Descumprimento de Preceito Fundamental somente existiria a partir de sua regulamentação por lei infraconstitucional, a qual traçaria as suas características ${ }^{5}$.

André Ramos Tavares (2001), porém, entende, adotando classificação das normas constitucionais proposta por Carlos Ayres Britto e Celso Bastos, tratar-se de norma auto-aplicável regulamentável. Significa dizer que, para o autor, a norma

Argumento este que não se sustenta. Verificamos que recentemente o Supremo Tribunal Federal, através da Argüição de Descumprimento Fundamental número 130, julgou a Lei 5.250/67, a chamada Lei de Imprensa, incompatível com a Constituição de 1988

${ }^{4}$ Conforme tradicional classificação de José Afonso da Silva.

${ }^{5}$ Agravo Regimental em Agravo de Instrumento n. 144.834-2-PR. 
da Argüição de Descumprimento de Preceito Fundamentalé de eficácia plena, podendo ser aplicada desde a sua entrada em vigor. A lei infraconstitucional reguladora apenas reforçaria o conteúdo da norma constitucional'.

O fato é que a posição adotada pelo Supremo Tribunal Federal, aliada ao longo período sem regulamentação via lei ordinária, contribuiu para a falta de debate doutrinário sobre $\mathrm{o}$ assunto.

\section{A lei reguladora: Lei 9.882, de 03 de dezembro de 1999}

Somente onze anos após a promulgação da Constituição, entrou em vigor a lei reguladora da Argüição de Descumprimento de Preceito Fundamental. ALei, segundo André Ramos Tavares (2001) e Daniel Sarmento (2001), definiu duas modalidades do instituto ora estudado.

A primeira é a Argüição de Descumprimento de Preceito Fundamental "autônoma", uma verdadeira ação direta para controle concentrado de constitucionalidade de atos normativos que não podem ser objeto de Ação Direta de Inconstitucionalidade. Conforme a jurisprudência do Supremo Tribunal Federal, temos, por exemplo, leis municipais, leis anteriores à constituição e leis revogadas. Até a entrada em vigor da Lei 9.882, de 03 de dezembro de 1999, não tínhamos nenhum mecanismo para o controle concentrado da constitucionalidade dessas espécies normativas.

A segunda é a Argüição de Descumprimento de Preceito Fundamental incidental que, para Tavares (2001), é a possibilidade de qualquer interessado, visualizando em seu processo particular lesão a direitos fundamentais, instaurar uma espécie de incidente que deslocaria o feito diretamente ao Supremo Tribunal Federal.

Porém, muito embora nossa Corte Constitucional reconheça a existência da Argüição de Descumprimento de Preceito Fundamental incidental (ADPF 3), o Tribunal não entende como ampla a sua legitimação. Apenas os enumerados pela Lei poderiam iniciar a Argüição de Descumprimento de Preceito Fundamental incidental (ADPF 11).

Já Sérgio Resende de Barros (2001) entende que a Lei reguladora é totalmente inconstitucional. Para o autor, a Argüição de Descumprimento de Preceito Fundamental, até pela sua nomenclatura, somente poderia ser entendida como um incidente e não como uma ação própria. Assim, entende que a Lei é inconstitucional, pois ampliou indevidamente a competência do Supremo, que só pode ser definida pelo texto constitucional, transformando até mesmo a chamada Argüição de Descumprimento de Preceito Fundamental incidental em verdadeira ação direta.

${ }^{6}$ Esta interpretação, em nosso entendimento, visa à máxima proteção dos direitos fundamentais e está em consonância com a moderna doutrina pós-positivista.
Leciona, ainda, que a legitimação é sempre ampla, competindo a qualquer interessado.

Contra a Lei reguladora da Argüição de Descumprimento de Preceito Fundamental, foi proposta uma Ação Direta de Inconstitucionalidade pelo Conselho Federal da Ordem dos Advogados do Brasil (ADIN 2231). Nela, o então Ministro Relator, Néri da Silveira, proferiu voto no sentido de se realizar uma interpretação da Lei conforme a Constituição. Entendeu o Ministro que constitucional é somente a argüição "autônoma", sendo que o texto constitucional não previu a hipótese de incidente de descumprimento de preceito fundamental. AAção Direta de Inconstitucionalidade ainda aguarda julgamento no Supremo Tribunal Federal.

A controvérsia doutrinária, exemplificada através das opiniões acima descritas, demonstra o grau de incerteza acerca do objeto da Argüição de Descumprimento de Preceito Fundamental. Com efeito, ainda não há meios objetivos, na doutrina, para se alcançar a definição do seu conteúdo.

Nenhum dos elementos da Argüição de Descumprimento de Preceito Fundamental foi definido pelo texto constitucional ou pela Lei reguladora. A expressão "preceitos fundamentais", por exemplo, aparece pela primeira e única vez, na Constituição, justamente no dispositivo que previu o instituto.

Isso nos leva à seguinte questão básica sobre o tema: para que serve a Argüição de Descumprimento de Preceito Fundamental? Trata-se de norma de eficácia limitada, como dispôs o Supremo Tribunal Federal? Se sim, a Argüição de Descumprimento de Preceito Fundamental vai ser aquilo que o legislador ordinário desejar, ou seja, a lei ordinária é livre para estabelecer a sua fisionomia, sem limites?

\section{A aparente inutilidade da Argüiçãa de Descumprimento de Preceito Fundamental}

A maneira como a doutrina e a jurisprudência tem tratado a Argüição de Descumprimento de Preceito Fundamental parece nos conduzir à conclusão de que o instituto é inútil e dispensável no sistema constitucional brasileiro.

Com efeito, Gilmar Mendes (2000), um dos membros participantes da comissão Celso Bastos, a qual foi responsável pela elaboração do projeto da Lei 9.882, de 03 de dezembro de 1999, fundamenta toda a validade da Argüição no sistema constitucional alemão, fonte inspiradora do instituto, segundo o autor.

Todavia, é importante lembrar que naquele sistema inexiste, por exemplo, a possibilidade de os juízes de primeiro grau declararem a inconstitucionalidade das leis. Tal papel compete privativamente ao Tribunal ConstitucionalAlemão (MARTINS, 2009; MENDES, 2000). Daí o erro em se justificar a Argüição de Descumprimento de Preceito Fundamental com fulcro no sistema tedesco.

Gilmar Ferreira Mendes (2000) entende a Argüição de Preceito Fundamental como 
um importante instrumento para pacificação da jurisprudência. É a oportunidade de a questão ser analisada pelo Supremo Tribunal Federal sem que milhares de processos sejam iniciados nas instâncias ordinárias e levem anos até chegar à Suprema Corte.

Com a devida vênia, já temos no nosso sistema mecanismos que cumprem esse papel. AAção Declaratória de Constitucionalidade tem a finalidade de tornar absoluta a presunção relativa de constitucionalidade das leis e atos normativos. Outro instrumento de uniformização da jurisprudênciaé a súmula vinculante, que tem efeitos gerais sobre todos os órgãos do Poder Judiciário e Executivo.

Assim, além de existirem outros meios para o desiderato apontado por Gilmar Mendes, é de se verificar ainda que a Argüição de Descumprimento de Preceito Fundamental é uma via estreita para tal função. Com efeito, o instituto se faz valer quando houver descumprimento de preceito fundamental. Assim, se o texto constitucional desejou tornar a Argüição de Descumprimento de Preceito Fundamental uma medida antecipatória da manifestação do Supremo Tribunal Federal, por que limitá-la somente às hipóteses onde fica caracterizado eventual descumprimento de preceitos fundamentais?

Em um segundo momento, pode-se extrair a utilidade da Argüição de Descumprimento de Preceito Fundamental como um mecanismo eficaz para controle de constitucionalidade de leis ou atos normativos que não podem ser objeto de Ação Direta de Inconstitucionalidade.

E é exatamente assim que a maioria da doutrina tem tratado a Argüição de Descumprimento de Preceito fundamental: como um verdadeiro sucedâneo da Ação Direta de Inconstitucionalidade.

Ainda que se considere constitucional tal assertiva, é de se verificar que a impossibilidade de controle amplo de constitucionalidade das leis e atos normativos em sede de Ação Direta de Inconstitucionalidade decorre da própria jurisprudência restritiva do Supremo Tribunal Federal. Isso quer dizer que o texto constitucional não proibiu que leis revogadas, leis municipais ou leis anteriores à Constituição sejam objeto de Ação Direta de Inconstitucionalidade. Tal conclusão foi exposta pelo próprio Supremo.

Em relação ao direito municipal, por exemplo, muito embora a literalidade do texto constitucional conduza, à primeira vista, à conclusão de que leis municipais estariam fora do objeto da Ação Direta de Inconstitucionalidade, o Supremo Tribunal Federal poderia, através de uma interpretação sistemática e extensiva ${ }^{7}$, considerálas possíveis objetos de Ação Direta de Inconstitucionalidade.

O Supremo Tribunal Federal já realizou esse tipo de interpretação em sede de

${ }^{7}$ Considerando-se, por óbvio, todos os princípios atinentes à hermenêutica constitucional, em especial a força normativa, a unidade, a máxima efetividade e o princípio da coloquialidade. Não podemos, outrossim, esquecer o conteúdo do próprio principio federativo.

REVISTA UNIARA, $n .^{0} 21 / 22,2008 / 2009$ controle concentrado de constitucionalidade. Com efeito, nossa Corte Suprema, antes da Emenda Constitucional 45/2004, através de uma interpretação extensiva, ampliou o rol dos legitimados para a propositura da Ação Direta de Inconstitucionalidade, para reconhecer a possibilidade de Governador de Distrito Federal propô-la (ADI-MC 645). O mesmo se diga em relação à lei distrital, cujo controle de constitucionalidade direto, via Ação Direta de Inconstitucionalidade, até hoje não contém previsão expressa no texto constitucional. Porém, o Supremo Tribunal Federal autoriza a propositura de Ações Diretas de Inconstitucionalidade em face das leis distritais.

De toda sorte, não parece ter sido esta a vontade do legislador constituinte, ou seja, criar um mecanismo específico para tal controle de constitucionalidade. Este, na verdade, foi desejo do legislador ordinário.

As opiniões doutrinárias sobre o tema, percebe-se, não apontam uma finalidade específica para a Argüição de Descumprimento de Preceito Fundamental. O pouco trato do assunto em sede constitucional contribui para a incerteza de seu objeto.

Mas, afinal, a Argüição de Descumprimento de Preceito Fundamental pode ser aquilo que o legislador originário quiser transformá-la? Pode o legislador traçar livremente os contornos da Argüição de Descumprimento de Preceito Fundamental estabelecida pelo texto constitucional?

A possível função da Argüição de Descumprimento de Preceito Fundamental

É certo que toda lei ordinária deve estar em perfeita harmonia com a Constituição Federal. Nesta medida, a lei reguladora da Argüição de Descumprimento de Preceito Fundamental deve explicitar a vontade do próprio texto constitucional, sob pena de inconstitucionalidade. Assim, devemos extrair a finalidade da Argüição de Descumprimento de Preceito Fundamental do texto constitucional. Em outras palavras, a lei não tem liberdade total para definir as características da argüição.

Em razão disto é que a lei 9.882/1999 é inconstitucional, pois ampliou indevidamente a competência do Supremo Tribunal Federal, bem como extrapolou os limites de regulação da matéria constitucional. Através de uma interpretação do texto constitucional, não parece coerente concluir que a Constituição desejou cindir o controle de constitucionalidade, de forma que certas modalidades de atos normativos fossem tratadas em Ações Diretas de Inconstitucionalidade e outras em sede de Argüição de Descumprimento de Preceito Fundamental.

Por outro lado, de acordo com a jurisprudência do Supremo Tribunal Federal, o legislador constituinte originário não produz(iu) normas constitucionais inconstitucionais. Desta feita, o Supremo Tribunal Federal afastou a doutrina acatada pelo Tribunal Constitucional Alemão sobre o tema. 
Porém, uma nova leitura do dispositivo da Argüição de Descumprimento de Preceito Fundamental talvez demonstre o equívoco do Supremo Tribunal Federal ${ }^{8}$ e, ainda, que o legislador constituinte originário se preocupou em prever um mecanismo de defesa de preceitos fundamentais contra o próprio texto constitucional.

O cerne da questão está no conteúdo da palavra "decorrente" contido no artigo 102, parágrafo único, da Constituição. A doutrina nos ensina que este vocábulo se refere à expressão "preceitos fundamentais". Quer dizer que o que decorre da Constituição são os "preceitos fundamentais". Estes, então, sofreriam descumprimento, o que ensejaria a propositura da Argüição de Descumprimento de Preceito Fundamental.

Porém, através de uma nova leitura, poderia se entender que o "decorrente" se refere ao termo "descumprimento". Quer dizer que, quando a própria Constituição Federal promover o descumprimento de preceitos fundamentais, caberia a referida Argüição a ser analisada pelo Supremo Tribunal Federal.

Neste prisma, a Argüição de Descumprimento de Preceito Fundamental serviria para combater normas constitucionais originárias ilegítimas. As normas constitucionais inseridas no texto constitucional através de emenda podem ser controladas pelos meios tradicionais, quando desrespeitarem o texto originário.

Conquanto esta leitura possa parecer, à primeira vista, uma interpretação do tipo "vale tudo", ela se demonstra coerente, especialmente considerando a época da realização dos trabalhos da Assembléia Constituinte. De fato, saíamos de um período de exceção, onde prevalecia a ditadura, inexistindo democracia. Razoável, portanto, concluir que o constituinte se preocupou em combater possíveis normas que viessem a contaminar os trabalhos da Assembléia Constituinte, prevendo então a Argüição de Descumprimento de Preceito Federal como um último recurso ao Supremo TribunalFederal.

Esta nova leitura demanda uma reformulação teórica do nosso sistema constitucional que, segundo doutrinadores e jurisprudência do Supremo Tribunal Federal, não aceita a possibilidade de declaração de inconstitucionalidade de normas constitucionais originárias, adotando-se principalmente a posição positivista em contraposição à pós-positivista ou neoconstitucionalista. Esse trabalho demanda uma ampla reformulação do Direito Constitucional, a começar pela própria teoria clássica do Poder Constituinte Originário.

De outra banda, os doutrinadores parecem concordar em relação à importância dos preceitos fundamentais. Sem entrar a fundo na conceituação doutrinária da expressão, os doutrinadores reconhecem uma espécie de supremacia de certas

${ }^{8}$ Pelo menos sob o aspecto da interpretação que deve ser dada às normas originárias. normas constitucionais, que ganhariam o status de preceitos fundamentais.

Esse posicionamento nos leva a concluir que preceitos fundamentais, como normas superiores que são, poderiam, em tese, estar em conflito com outras normas constitucionais originárias. Neste conflito, mereceriam destaque as primeiras normas, ainda que através de uma interpretação conforme a constituição. Precisaríamos, então, de um mecanismo que, através de uma técnica de decisão judicial, firmasse a melhor interpretação para aquele conflito entre normas originárias.

É quase impossível entender a finalidade - ou utilidade - da Argüição de Descumprimento de Preceito Fundamental sem que possamos considerar certas normas mais importantes que outras no sistema constitucional.

Com efeito, segundo André Ramos Tavares (2001), a expressão "fundamental" não é sinônimo de "constitucional". Vale dizer que nem toda norma constitucional é um preceito fundamental. Preceitos fundamentais são aqueles que estão na base, que formam o núcleo estruturante do nosso sistema jurídico-constitucional, imprescindível à existência digna da pessoa humana, o mínimo invulnerável a que todos têm direito.

O reconhecimento da existência de preceitos fundamentais contidos no texto constitucional só nos pode levar à idéia de que estas normas são superiores a outras normas também constitucionais.

Neste diapasão, então, esta seria (é) a finalidade maior da Argüição de Descumprimento de Preceito Fundamental: extinguir do texto constitucional normas constitucionais originárias ${ }^{9}$ descumpridoras de preceitos fundamentais.

Esta nova leitura do dispositivo constitucional merece maior atenção tanto pela doutrina quanto pelo Supremo Tribunal Federal. Talvez tenha sido desejo do legislador constituinte originário o controle da legitimidade do próprio texto constitucional originário.

A possibilidade de se controlar a legitimidade das normas constitucionais originárias é uma evolução em relação à teoria clássica do poder constituinte originário, que o entende como ilimitado juridicamente. Assim, a Argüição de Descumprimento de Preceito fundamental serviria (ou serve) para fixar o correto sentido dado ao texto inicial, superando-se o positivismo clássico ${ }^{10} \mathrm{e}$ partindo para uma hermenêutica constitucional onde o exegeta está inserido no mundo dos fatos e acrescentando, por consequiência, um conteúdo valorativo (em diversos graus) ao texto constitucional originário.

${ }^{9}$ Lembramos que norma não é sinônimo de texto legal.

${ }^{10}$ Que exclui o conteúdo axiológico da norma. 


\section{Conclusões}

A Argüição de Descumprimento de Preceito Fundamental é apontada, pela doutrina, como uma espécie de mecanismo de controle de constitucionalidade.

Todavia, a doutrina majoritária e a jurisprudência do Supremo Tribunal Federal não apontam uma função específica para a Argüição de Descumprimento de Preceito Fundamental. Mesmo aqueles que consideram a lei reguladora inconstitucional, apontam o vício por fundamentos diversos.

É certo que o texto constitucional não deu liberdade total ao legislador ordinário para fazer o que bem entender do instituto. Vale dizer que seu objeto e finalidade devem ser extraídos através de interpretação sistemática de toda a Constituição, inclusive tendo por base os valores políticos e sociológicos que impulsionaram os trabalhos da Assembléia Constituinte.

Neste sentido, neste artigo, foi proposta uma nova leitura do dispositivo constitucional, de forma a se considerar que a expressão "decorrente" se refere ao termo "descumprimento". Quer dizer que a Constituição talvez tenha previsto um mecanismo de controle de legitimidade das próprias normas constitucionais originárias através da Argüição de Descumprimento de Preceito Fundamental.

Esta nova leitura constitucional demanda uma nova visão do Direito Constitucional Moderno, especialmente sobre a teoria clássica do poder constituinte e a sua adequada interpretação.

\section{Referências bibliográficas:}

ARAUJO, Luiz Alberto David; NUNES JÚNIOR, Vidal Serrano. Curso de direito constitucional. 9. ed. São Paulo: Saraiva, 2005.

BACHOF, Otto. Normas constitucionais inconstitucionais. Coimbra: Livraria Almedina, 1994.

BARROS, Sérgio Resende de. O nó górdio do sistema misto. In: ROTHENBURG, Walter Claudius; TAVARES, André Ramos. Argüição de descumprimento de preceito fundamental: análises à luz da lei no. 9.882/ 1999. São Paulo: Atlas, 2001.

BARROSO, Luis Roberto. Interpretação e aplicação da constituição. 7. ed. São Paulo: Saraiva, 2009.

BONAVIDES, Paulo. Curso de direito constitucional. 22. ed. São Paulo:
Malheiros, 2008

BRANCO, Paulo Gustavo Gonet; COELHO, Inocêncio Mártires; MENDES, Gilmar Ferreira. Curso de direito constitucional. 3.ed. São Paulo: Saraiva, 2008

CHAI, Cássius Guimarães. Descumprimento de preceito fundamental: identidade constitucional e vetos à democracia. Belo Horizonte:

Mandamentos, 2004.

FAZOLI, Carlos Eduardo de Freitas. Princípios jurídicos. Revista Uniara, v.20, p.13-29.2007.

MARTINS, Ives Gandra da Silva Martins; MENDES, Gilmar Ferreira. Controle concentrado de constitucionalidade: comentários à Lei. 9.868, de 10-111999. 3. ed. São Paulo: Saraiva, 2009.

MENDES, Gilmar. Argüição de descumprimento de preceito fundamental: demonstração de inexistência de outro meio eficaz. Jus Navigandi, Teresina, v.4, n.43, jul. 2000. Disponível em: <jus2.uol.com.br/doutrina/texto.asp?id=236> . Acesso em: 01 maio 2009

MIRANDA, Jorge. Manual de direito constitucional. 3. ed. Coimbra: Coimbra Editora, 1996. (tomo II).

SARMENTO, Daniel. Apontamentos sobre a argüição de descumprimento de preceito fundamental. In: ROTHENBURG Walter Claudius; TAVARES, André Ramos. Argüição de descumprimento de preceito fundamental: análises à luz da lei no. 9.882/1999. São Paulo: Atlas, 2001.

STRECK, Lênio Luiz. Jurisdição constitucional e hermenêutica: uma nova crítica do direito. 2. ed. Rio de Janeiro: Forense, 2004.

TAVARES, André Ramos. Tratado da argüição de preceito fundamental: (Lei. nº 9.868/99 e Lei no 9.882/99). São Paulo: Saraiva, 2001.

Title:

ACCUSATION OF BREACH OF FUNDAMENTAL PRECEPT: A 


\section{MECHANISM TO CONTROL THE ORIGINARY CONSTITUCIONAL}

\section{REQUIREMENTS}

\section{Abstract:}

There is still no consensus in the literature about the object and purpose of the accusation of breach of fundamental precept. It is true that the Office should be interpreted in the light of the Constitution and not of the ordinary law. In this sense, it can be an important tool in the defense of fundamental principles considering the originary constitutional rules.

Keywords: Constitutional Law, Accusation of Breach of Fundamental Precept,

Originary Constitutional Standards, Control. 